v.23, n.3, Especial do $3^{\circ}$ Workshop de Nutrição de Animais Selvagens da AZAB, p.61-64, 2018

\title{
Preferência alimentar de uma fêmea e um filhote de Dasypus novemcinctus (Linnaeus, 1758) em cativeiro
}

\author{
Carolyne Assis Eigenheer Pinke Testa ${ }^{1}$; Patrícia Sammarco Rosa ${ }^{2}$; Thiago Ferla Novais Castro ${ }^{3}$; Alícia \\ Giolo Hippólito ${ }^{1}$; Barbara Sardela Ferro ${ }^{1}$; Alessandra Melchert ${ }^{4}$. \\ ${ }^{1}$ Pós-gradução em Animais Selvagens, Faculdade de Medicina Veterinária e Zootecnia, UNESP, Campus de \\ Botucatu/SP, Departamento de Clínica Veterinária, \\ ${ }^{2}$ Pesquisador Científico, Instituto "Lauro de Souza Lima”, Bauru/SP, Diretora de Ensino e Pesquisa. \\ ${ }^{3}$ Graduação em Ciências Biológicas - Bacharelado, Universidade do Sagrado Coração, USC, Bauru/SP. \\ ${ }^{4}$ Docente, Faculdade de Medicina Veterinária e Zootecnia, UNESP, Campus de Botucatu/SP, Departamento \\ de Clínica Veterinária. \\ Email: carolyne.pinke@gmail.com.br
}

RESUMO: Em cativeiro, as dietas para Dasypus novemcinctus, em geral, constituem-se de proteína animal misturadas com frutas, verduras e suplemento vitamínico-mineral. Porém, não há estudos relacionados com a preferência alimentar de tatus em cativeiro. Assim, o objetivo deste estudo foi avaliar a preferência alimentar de uma fêmea adulta e de um filhote mantidos em cativeiro, expostos a quatro dietas com origem e porcentagens proteicas diferentes. Desta forma, o experimento foi realizado durante cinco semanas, sendo que as quatro primeiras semanas foi um período de manejo preliminar e a quinta semana foi realizada a coleta dos dados. A preferência alimentar, segundo a frequência de consumo, foi diferente para mãe e filhote, sendo que o filhote apresentou uma maior preferência pela dieta 1 e a mãe procurou igualmente as dietas. Quanto ao consumo, a dieta 1 apresentou maior ingestão. Assim, conclui-se que a preferência alimentar do filhote está em consonância ao requerimento proteico da espécie e a mãe apresentou um comportamento alimentar diverso, relacionado ao seu comportamento de espera de escolha do filhote.

Palavras-chave: adaptação alimentar; comportamento alimentar; dieta; tatu-galinha.

\section{INTRODUÇÃO}

O Dasypus novemcintus é uma espécie terrestre, solitária e possui hábito crepuscular/noturno (MEDRI et al, 2006; SUPERINA et al, 2014). Possui a poliembrionia como característica biológica, produzindo quatro filhotes por gestação, todos do mesmo sexo (MEDRI et al, 2006; SUPERINA et al, 2014). Os filhotes nascem totalmente formados, com os olhos abertos e o desmame ocorre com quatro a cinco meses (MEDRI et al, 2006). $\mathrm{Na}$ natureza, alimentam-se de invertebrados, frutas, pequenos vertebrados, ovos e alguns fungos, possuindo uma variação sazonal de sua dieta (MEDRI et al, 2006; ROSA et al, 2009; CORRÊA VAZ et al, 2012; WHITAKER Jr. et al., 2012; SUPERINA et al., 2014; SILVA et al, 2015). A morfologia de seu sistema digestório aponta para uma melhor adaptação ao aproveitamento proteico, principalmente proveniente de insetos (CARVALHO et al, 2014). Em cativeiro, Superina et al. (2014) sugere algumas dietas e cita dietas utilizadas por outros autores. Em geral, as dietas constituem-se de proteína animal misturadas com frutas, verduras e suplemento vitamínicomineral. No entanto, a adaptação à dieta artificial costuma ser de difícil 
realização, principalmente com animais mais velhos, sendo recomendado oferecer vários tipos de alimentos para os animais determinarem sua preferência (SUPERINA et al., 2014). Porém, não há estudos relacionados com a preferência alimentar de tatus em cativeiro. Assim, o objetivo deste estudo foi avaliar a preferência alimentar de uma fêmea adulta e de um filhote mantidos em cativeiro, expostos a quatro dietas com origem e porcentagens proteicas diferentes.

\section{MATERIAL E MÉTODOS}

Uma fêmea foi capturada e mantida em cativeiro no Instituto "Lauro de Souza Lima", na cidade de Bauru/SP. No dia 11/10/2017, houve o nascimento de quatro filhotes machos, porém somente um sobreviveu. Mãe e filho foram mantidos juntos, na mesma baia, durante todo o período de amamentação, adaptação do filhote à dieta sólida e da avaliação da preferência alimentar. Foram formuladas e fornecidas quatro dietas experimentais: dieta 1 constituída por ração canina e carne bovina, apresentando $24 \%$ de proteína total, sendo que, deste total, $10 \%$ é de proteína de origem animal; dieta 2 constituída por ração canina, ovos de galinha com gema e carne bovina, apresentando $24 \%$ de proteína total, sendo que, deste total, $13 \%$ é de proteína de origem animal; dieta 3 constituída por ração canina, mamão, banana e carne moída, com 19,9\% de proteína total, sendo que, deste total, $8 \%$ é de proteína de origem animal; dieta 4 constituída por ração canina, ovos de galinha com gema, mamão, banana e carne moída, com $21 \%$ de proteína total, sendo que, deste total, $11 \%$ é de proteína de origem animal. As dietas tiveram inclusão de água para amolecimento da ração, todas com a mesma proporção. O experimento foi realizado de acordo com o proposto por Fekete et al. (2005) e teve duração total de cinco semanas. As quatro primeiras semanas foi um período de manejo alimentar preliminar, no qual as quatro dietas foram oferecidas isoladas $e$ alternadamente. Na quinta semana, foi realizada efetivamente a avaliação da preferência alimentar, no qual os animais receberam as quatro dietas juntas, em tigelas separadas, e a ordem de arranjo das tigelas nas baias era alternada diariamente. Foi calculada a ingestão alimentar diária dos animais em conjunto e foi registrada a ordem de consumo das dietas individualmente nos primeiros 30 minutos de oferta para determinação da frequência de consumo de cada dieta. A análise estatística foi descritiva (Processo CEUA n 0203/2017 - FMVZ/UNESP; SISBIO nำ60819-1).

\section{RESULTADOS E DISCUSSÃO}

A frequência de consumo e, consequentemente, a preferência alimentar, foi diferente para mãe e filhote. $O$ filhote apresentou, visualmente, maior procura pela dieta 1 , porém no terceiro dia de observação, o filhote apresentou maior procura pela dieta 4. Por outro lado, a mãe apresentou uma busca mais homogênea entre as dietas, com exceção da dieta 3 (Tabela 1). Contudo, no primeiro dia de observação, a mãe teve uma frequência alimentar maior para a dieta 4 e no último dia de observação, a frequência foi maior para a dieta 1 (Tabela 1).

\begin{tabular}{|c|c|c|c|c|c|c|c|}
\hline & & \multicolumn{6}{|c|}{ DIAS DE OBSERVAÇÃO } \\
\hline & & 1 & 2 & 3 & 4 & 5 & 6 \\
\hline \multirow{4}{*}{$\begin{array}{l}\text { ㅁ } \\
\text { 오 } \\
\text { ․ㅏㄴ }\end{array}$} & DIETA 1 & 0,33 & 1,00 & 0,00 & 0,60 & 0,50 & 0,45 \\
\hline & DIETA 2 & 0,00 & 0,00 & 0,00 & 0,00 & 0,00 & 0,00 \\
\hline & DIETA 3 & 0,33 & 0,00 & 0,33 & 0,20 & 0,00 & 0,36 \\
\hline & DIETA 4 & 0,33 & 0,00 & 0,67 & 0,20 & 0,50 & 0,18 \\
\hline \multirow{4}{*}{ 崖 } & DIETA 1 & 0,20 & 0,33 & 0,33 & 0,33 & 0,50 & 0,60 \\
\hline & DIETA 2 & 0,20 & 0,00 & 0,33 & 0,33 & 0,50 & 0,00 \\
\hline & DIETA 3 & 0,20 & 0,33 & 0,00 & 0,33 & 0,00 & 0,00 \\
\hline & DIETA 4 & 0,40 & 0,33 & 0,33 & 0,00 & 0,00 & 0,40 \\
\hline
\end{tabular}


Quando analisamos o cálculo de ingestão alimentar diário das dietas (Tabela 2), observamos que houve maior consumo da dieta 1 em todos os dias de observação, porém no primeiro, houve consumo da dieta 2 , semelhante ao da dieta 1. Já no terceiro e sexto dia, houve consumo da dieta 4 , semelhante ao da dieta 1 (Tabela 2). A média de consumo de todos os dias observados, foi maior para a dieta 1 (Tabela 2).

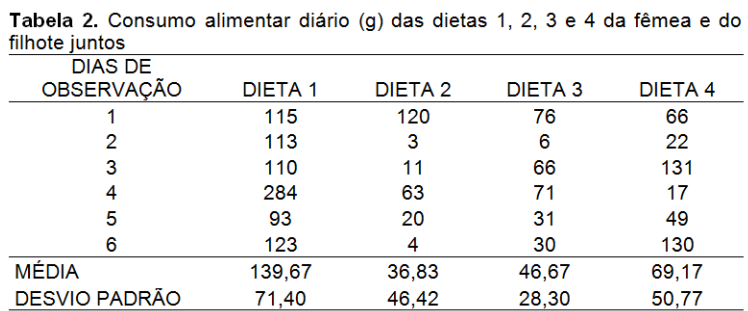

A diferença de preferência entre mãe e filho pode estar relacionado ao fato de terem sido alimentados juntos, o que fazia com que a mãe esperasse o início do consumo do filhote para então iniciar o seu consumo. Durante as observações, este comportamento da mãe de esperar o filhote escolher e iniciar o consumo foi observado em todos os dias e, conforme o filhote trocava de dieta a mãe interrompia seu consumo e aguardava o filhote, para então reiniciar o consumo do alimento. Este comportamento da mãe também pode explicar o fato de sua frequência de consumo não apresentar uma única dieta com maior preferência, mas sim uma frequência de consumo similar entre as dietas. Tanto a mãe quanto o filhote, desprezaram a dieta 3, com menor porcentagem de proteína total $(19,9 \%)$ e de origem animal $(8 \%)$. Este comportamento pode estar relacionado à porcentagem de proteína, visto que tatus da espécie Dasypus novemcintus demonstraram, em trabalhos de Ramsey e colaboradores (1981), consumirem, na natureza, uma dieta com porcentagem proteica de $22,4 \%$. Além disso, o seu trato digestório é adaptado para um melhor aproveitamento proteico proveniente de insetos, conforme verificado por Carvalho e colaboradores (2014), o que podemos inferir que dietas com maior aporte proteico, principalmente de origem animal, esteja em maior conformidade com as necessidades nutricionais da espécie, interferindo na preferência alimentar, como foi observado com a maior ingestão média da dieta 1.

\section{CONCLUSÃO}

A preferência alimentar do filhote está em consonância ao requerimento proteico da espécie, entretanto, a mãe apresentou um comportamento alimentar diverso, não apresentando uma única dieta de preferência, relacionado ao seu comportamento de espera de escolha do filhote.

\section{AGRADECIMENTOS}

Ao Instituto "Lauro de Souza Lima" por todo apoio institucional, de infra-estrutura e pessoal ao longo da realização deste trabalho. À Fruta Nobre - CEASA Bauru pelo fornecimento das frutas utilizadas no experimento.

\section{REFERÊNCIAS}

CARVALHO, M.M; PIERI, N.C.G.; PEREIRA, K.F.; LIMA, F.C.; CARNIATTO, C.H.O.; MIGLINO, M.A.; RICCI, R.E.; MARTINS, D.S. Caracterização comparativa do intestino das espécies da Ordem Xenarthra. Pesq. Vet. Bras., vol.34, supl.1, p.4956, 2014.

CORRÊA VAZ, V.; SANTORI, R.T.; JANSEN, A.M.; DELCIELLOS, A.C.; D'ANDREA, P.S. Food habits of armadillos (Cingulata, Dasypodidae) and Anteaters (Pilosa, Myrmecophagidae) at Serra da Capivara National Park (Piauí State, Brazil). Edentata, 13:84-89, 2012. 
FEKETE, S.G.; FODOR, K.; PROHÁCZIK, A.; ANDRÁSOFSZKY, E. Comparison of feed preference and digestion of three different commercial diets for cats and ferrets. Journal of Animal Physiology and Animal Nutrition, vol. 89, p.199-202, 2005.

MEDRI, I.M.; MOURÃO, G.M.; RODRIGUES, F.H.G. Ordem Xenarthra. In: Mamíferos do Brasil. (REIS et al, ed.) Londrina, Brasil: Nélio R. dos Reis, p. 71-99, 2006.

RAMSEY, P.R.; TYLER, D.F.; WADDIL,J.R.; STORRS, E.E. Blood chemistry and nutritional balance of wild and captive armadillos (Dasypus novemcinctus L.). Comp Biochem and Physiol Part A: Physiol., v.69, n.3, p.517-521, 1981.

ROSA, P.S.; PINKE, C.A.E.; PEDRINI, S.C.B.; SILVA, E.A. The effect of iron supplementation in the diet of Dasypus novemcinctus (Linnaeus, 1758) armadillos in captivity. Brazilian Journal of Biology, v.69, n.1, p.117122, 2009.

SILVA, K.F.M.; COSTA, J.F.; ANACLETO, T.C.S.; TIMO, T.P.C. Avaliação do Risco de Extinção de Dasypus novemcinctus Linnaeus, 1758 no Brasil. Processo de avaliação do risco de extinção da fauna brasileira. ICMBio, 2015. Disponível em: <http://www.icmbio.gov.br/portal/biodiver sidade/fauna-brasileira/lista-deespecies/ 7106mamiferos-dasypus-novemcintustatu-galinha.html>. Acessado em 07 de junho de 2017.

SUPERINA, M.; BRIEVA, R.C.; AGUILAR, R.F.; TRUJILLO, F. Manual de mantenimiento y rehabilitación de armadillos. Fundación Omacha, ODL, Cormacarena, Corporinoquia, Corpometa y Bioparque Los Ocarros: Bogotá, Colômbia, 2014. 96p.
WHITAKER Jr., J.O.; RUCKDESCHEL, C.; BAKKEN, L. Food of the armadillo Dasypus novemcinctus $L$. from Cumberland Island, GA. Southeastern Naturalist, vol.11, n.3, p.487-506, 2012.

Agradecemos ao apoio da Fundação Araucária e da Coordenação de Aperfeiçoamento de Pessoal de Nível Superior - CAPES na realização do $3^{\circ}$ Workshop de Nutrição de Animais Selvagens.
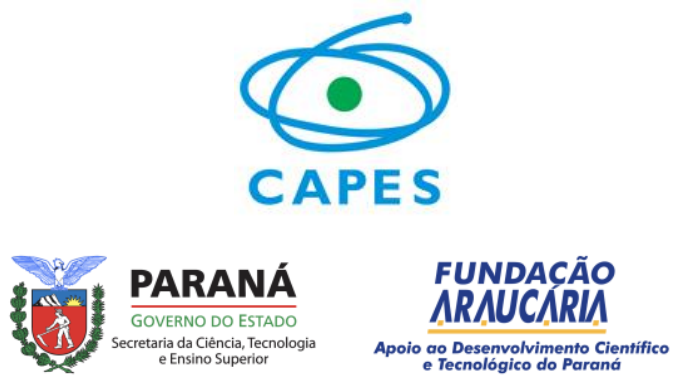